\title{
Mateusz Marciniak
}

Uniwersytet im. Adama Mickiewicza w Poznaniu

E-MAIL: mateusz.marciniak@amu.edu.pl

\section{Łukasz Goryszewski, Style konsumpcji polskiej klasy wyższej, NOMOS, Kraków 2014, 293 strony}

\begin{abstract}
STRESZCZENIE
W tekście dokonano omówienia i podjęto dyskusję ze studium Łukasza Goryszewskiego Strle Konsumpcji polskiej Klasy wyższej (2014). W sytuacji wielości dostępnych lektur dotyczących zjawiska konsumpcji warto zwrócić uwagę na tę pozycję, gdyż dotyczy zagadnienia stylów konsumpcji specyficznej grupy - polskiej klasy wyższej. Tematyka bogactwa jest silnie obecna na łamach prasy codziennej, ale stosunkowo rzadko trafia na warsztat badawczy, zwłaszcza empiryczny - badania dotyczące bogactwa są zdecydowanie zaniedbane w porównaniu z badaniami biedy. Dzięki pracy Łukasza Goryszewskiego uzyskujemy wgląd w style konsumpcji (wybranych dóbr i usług: samochodów, ubrań, mieszkań oraz sposobów spędzania czasu wolnego) przedstawicieli polskiej klasy wyższej. Dopełnienie uzyskanego obrazu stanowi analiza wizerunku polskich elit, nakreślonego $\mathrm{w}$ wybranych serialach oraz czasopismach.

SŁOWA KLUCZOWE: kultura konsumpcyjna, style konsumpcji, klasa wyższa, bogactwo.
\end{abstract}

Konsumpcja jest jedną z istotniejszych kategorii analitycznych współczesnego społeczeństwa i jego kultury. Uznawana bywa wręcz za kluczową kategorię, co znajduje odzwierciedlenie w wielości określeń rzeczywistości odwołujących się do niej (np. społeczeństwo konsumpcyjne, kultura konsumpcyjna czy świat konsumpcji). Konsumpcja jest kategorią interdyscyplinarną, zajmują się nią m.in. przedstawiciele nauk ekonomicznych, ekolodzy, kulturoznawcy, psycholodzy, filozofowie, historycy, antropolodzy, pedagodzy, etnolodzy czy też socjolodzy. Dlaczego w sytuacji mnogości dostępnych lektur poświęconych zjawisku konsumpcji warto zwrócić uwagę na pozycję Łukasza Goryszewskiego STYLE KONSUMPCJI POLSKIEJ KLASY WYŻsZej?

Odpowiadając na powyższe pytanie warto zwrócić uwagę przede wszystkim na wybór tematyki badawczej, która jest niezwykle interesująca. Łukasz Goryszewski postanowił bowiem zgłębić zagadnienie stylów konsump- 
cji wybranej przez siebie grupy - polskiej klasy wyższej. Jeśli potraktować polskie społeczeństwo jako spolaryzowane, to badania dotyczące bogactwa są zdecydowanie zaniedbane w porównaniu z badaniami biedy ${ }^{1}$. Tematyka bogactwa jest silnie obecna na łamach prasy codziennej, ale stosunkowo rzadko trafia na warsztat badawczy, zwłaszcza empiryczny ${ }^{2}$. Jeśli chodzi natomiast o badania i analizy struktury społeczeństwa polskiego, to mamy dość bogatą literaturę dotyczącą klasy średniej, w tym także jej stylów życiaª mniej wiemy natomiast o stylu życia klasy wyższej. Recenzowana praca stanowi zatem istotne uzupełnienie dostępnej literatury.

Recenzowana książka wpisuje się w nurt badań nad strukturą społeczną, a zatem odwołuje się do prób kategoryzowania społeczeństwa. Autor, jak sam pisze - uległ „zafascynowaniu” nie tyle „najbardziej uprzywilejowaną” klasą społeczną, co „wyrazem nierówności społecznych” w postaci „konsumpcji dóbr i usług" [s. 10]. W swojej pracy postawił i poddał weryfikacji hipotezę, zgodnie z którą „style konsumpcji polskiej klasy wyższej w wybranych sferach konsumpcji są $\mathrm{w}$ dużym stopniu uwarunkowane przez pozycję klasową, jaką jej reprezentanci zajmowali poprzednio" [s. 11]. Publikacja ma charakter typowego studium teoretyczno-empirycznego.

W rozdziale pierwszym Goryszewski szczegółowo zarysowuje mapę klasycznych podejść w teorii konsumpcji i teorii klas, śledząc przy tym rozwój obu tych grup konceptów. Dobór autorów wpisuje się w perspektywę teoretyczną przyjętą przez Autora. Przywołane zostają zatem koncepcje Marksa, Veblena czy Bella. Liczne są także odwołania do prac Aldridge’a, Bywalca, Baudrillarda, Galbraitha czy Ritzera. Analizy Goryszewskiego z mocą unaoczniają, jak konsumpcja (w tym szczególnie ostentacyjna) klas dominujących (uprzywilejowanych) wpływa na całokształt społeczeństwa oraz jakie funkcje pełniła i pełni we współczesnej gospodarce kapitalistycznej i zachowaniach społecznych. Rozdział ten jest stosunkowo obszerny i może być mało czytelny - podzielony został bowiem zaledwie na dwie części (zgodnie z perspektywą chronologiczną). Warto byłoby uporządkować zestawione informacje według czytelnego klucza - jak czyni to chociażby Roberta Sassatelli

Chociażby prace Elżbiety Tarkowskiej oraz jej współpracowników, np. Dyskursy ubóstwa i wykluczenia społecznego, E. Tarkowska (red.), IFiS PAN, Warszawa 2013.

2 Zob. np. Zmiany w życiu Polaków w gospodarce rynkowej, L. Beskid (red.), IFiS PAN, Warszawa 1999; Polacy równi i równiejsi, M. Jarosz (red.), Instytut Studiów Politycznych PAN, Warszawa 2010.

3 Zwłaszcza prace H. Domańskiego, np. Polska klasa średnia, Wydawnictwo Uniwersytetu Wrocławskiego, Wrocław 2002. 
analizując trendy w rozwoju kultury konsumpcyjnej. . W rozdziale tym przeważają odwołania do autorów zagranicznych, nieliczne są zaś odwołania do autorów polskich (oprócz Czesława Bywalca). Nie podważa to wartości analiz Goryszewskiego, niemniej przywołanie prac polskich badaczy ${ }^{5}$, pozwoliłoby na bezpośrednie odniesienie do analiz konsumpcji w warunkach polskich.

W rozdziale drugim Autor skupia się na socjologicznej analizie społeczeństwa polskiego, osadzając rozważania w koncepcjach klasowych Webera, Marksa, Veblena czy Bourdieu. Wypracowuje definicję współczesnej polskiej klasy wyższej w oparciu o system schematów Erikson-Goldthorpe-Portocarere (EGP) oraz schemat Wrighta. Zgodnie z przyjętymi przez siebie założeniami, do klasy wyższej zalicza głównie ludzi ze świata biznesu: posiadaczy środków produkcji, przedsiębiorców zatrudniających co najmniej 50 osób, czy menedżerów - przedstawicieli rad nadzorczych i prezesów firm (zarówno publicznych, jak i prywatnych).

Wyłonienie przez Goryszewskiego klasy wyższej w analizie społeczeństwa polskiego może budzić kontrowersje, toteż zajmiemy się nieco obszerniej kwestią. Analiza klasowa/warstwowa społeczeństwa polskiego budzić może wątpliwości, bowiem część badaczy kwestionuje istnienie klasy wyższej w Polsce 6 . Wobec zaniku tradycyjnych wyznaczników struktury społecznej (stanowiącej wyznacznik orientacji kulturowych poszczególnych grup społecznych) niektórzy badacze podważają zasadność posługiwania się pojęciem klasy społecznej. Goryszewski dokonuje krótkiego przeglądu teorii klasowych [s. 84-88], ale nie odnosi się do krytyków tych koncepcji. Co prawda wraca do tego wątku w zakończeniu książki, ale podejmuje dość ograniczoną dyskusję. Odnosi się tylko do oceny polskiej klasy wyższej, sformułowanej przez Domańskiego, podważając elementy jego definicji głównie ilustracjami z prasy codziennej. Wydaje się, że w tak kluczowej kwestii konieczne byłoby odwołanie się do argumentów innych socjologów (np. Jacka Wasilewskiego, Stanisława Kozyra-Kowalskiego), i usytuowanie definicji Autora wobec takich kategorii, jak mikroklasa, quasi-klasa itp.

Bazując na koncepcji Bourdieu, Goryszewski członków klasy wyższej określa jako posiadaczy największych zasobów kapitału ekonomicznego, spo-

4 Roberta Sassatelli (2007, s. 41-55) wyłania dziesięć trendów w rozwoju kultury konsumpcyjnej. Dotyczą one: handlu, rodzaju produkcji, systemu finansowego, pojęcia luksusu, etyki światowej, mody, systemu komercyjnego, przemysłu czasu wolnego oraz dominującego dyskursu publicznego.

5 Zagadnienie społecznych funkcji konsumpcji (w tym także jej stylów) analizie poddają chociażby tacy autorzy jak Felicjan Bylok (2005) czy Wiesław Wątroba (2009).

6 H. Domański, op. cit.; idem, Społeczeństwa europejskie. Stratyfikacja i systemy wartości, Wydawnictwo Naukowe Scholar, Warszawa 2009. 
łecznego i kulturowego, a w konsekwencji symbolicznego. Wśród jej przedstawicieli skupił się na frakcji najbardziej dominującej - posiadającej najwięcej kapitału ekonomicznego. Tym samym w poczet ludzi „najpotężniejszych” zostali ujęci ludzie najbogatsi, kontrolujący środki produkcji, niezależni od reszty społeczeństwa dzięki swej sile ekonomicznej (nie zostali tu zaliczeni inteligenci czy zubożali arystokraci). Jest to dyskusyjne, bowiem jedynym kryterium wyróżniania warstw w takim ujęciu staje się ekonomiczne - pomijane są natomiast odmienne przyczyny bogactwa, co w świetle analiz Davida S. Landesa ${ }^{7}$ wydaje się być nieuzasadnione.

Rozdział trzeci pozwala na płynne przejście do części empirycznej książki. Goryszewski przedstawia w nim zwięźle założenia metodologiczne swojego projektu. Wiele miejsca poświęca uzasadnieniu metod i technik oraz procedury badawczej (z triangulacją metodologiczną) zastosowanych w badaniach interesującego go zjawiska. Wywiady jakościowe przeprowadził zarówno z przedstawicielami polskiej klasy wyższej, jak i osobami zatrudnionymi w przemyśle towarów luksusowych. Na szczególne wyróżnienie w tej części pracy zasługują uwagi Autora dotyczące trudności wynikających z prowadzenia badań socjologicznych wśród trudno dostępnych grup, a za taką można uznać przedstawicieli elit społecznych. Trudno się zatem dziwić, że mamy niewiele badań w kręgach bogactwa, a to dodatkowo wyróżnia tę publikację na tle innych, dotyczących konsumpcji ${ }^{8}$.

Wyniki badań nad stylami konsumpcji polskiej klasy wyższej stają się przedmiotem kolejnego rozdziału. Jako punkt odniesienia analiz zgromadzonego materiału Autorowi posłużyły koncepcje Veblena oraz Bourdieu. Wyłonił cztery sfery konsumpcji, które w wypowiedziach badanych zajmowały stosunkowo najwięcej miejsca. Kolejno analizuje samochody, ubrania, mieszkania oraz sposoby spędzania czasu wolnego respondentów. W ten sposób w czterech podrozdziałach uzyskujemy szczegółowy (blisko stustronicowy!) wgląd w styl konsumpcji przedstawicieli polskiej klasy wyższej. Dopełnienie uzyskanego obrazu stanowi analiza medialnego wizerunku. Jak przeko-

D. S. Landes, Bogactwo i nędza narodów: dlaczego jedni sa tak bogaci, a inni tak ubodzy, MUZA, Warszawa 2010.

8 Badanie konsumpcji (w tym także jej stylów w poszczególnych grupach) często ogranicza się do grup łatwo dostępnych, posiadamy zatem stosunkowo duży zakres wiedzy o konsumpcji przeciętnych obywateli, a zwłaszcza młodzieży akademickiej, A. M. Zawadzka, J. Duda, Zakupy, zadowolenie z życia i aspiracje życiowe, czyli jakie zakupy i komu moga podwyższać zadowolenie z życia?, [w:] W supermarkecie szczęścia. O różnorodności zachowań konsumenckich w kontekście jakości życia, M. Grónik-Durose, A. M. Zawadzka (red.), Difin, Warszawa 2012, s. 133-158; L. Nowak, Uwarunkowania zachowań konsumenckich młodzieży akademickiej. Eksploracja struktur ukrytych, Wydawnictwo Uniwersytetu Ekonomicznego w Poznaniu, Poznań 2009. 
nująco wyjaśnia sam Goryszewski, jest ona uzasadniona o tyle, że przekazy medialne nie tylko odzwierciedlają (czasami zniekształcając) style konsumpcji, ale też je konstruują [s. 220]. Prawie trzydzieści stron studium jest poświęconych analizie polskich seriali, zwłaszcza "Rezydencji” oraz dwóch czasopism: „Sukcesu” oraz „Essence”.

Omówiona dotychczas część książki jest zajmująca nie tylko ze względu na bogate ilustracje (przytaczane fragmenty wypowiedzi respondentów lub artykułów prasowych) charakteryzowanych sfer konsumpcji, ale także dzięki ich klasyfikacjom bądź typologizacjom (np. typologia ubrań) oraz klarownym podsumowaniom Autora. Dzięki temu - zastosowanym rozwiązaniom technicznym, sposobowi prowadzenia analiz, podobnie jak dzięki klarownej części metodologicznej, książkę tę można uznać za wzorzec dobrej praktyki badań jakościowych. Może służyć jako pomoc dydaktyczna, przydatna wskazówka dla przedstawicieli nauk pedagogicznych (i innych społecznych) w przypadku projektowania, prowadzenia i analizowania wyników badań jakościowych (w tym z wykorzystaniem analizy dokumentów oraz studium przypadku).

Ostatni z rozdziałów swojej pracy Goryszewski poświęca interpretacji zgromadzonego materiału. Szczególnie wartościowe jest zestawienie wyników badań własnych Autora z rezultatami podobnych badań sprzed 20 lat i wskazanie najistotniejszych różnic i podobieństw między nimi. Godna uwagi jest też próba nakreślenia stylu konsumpcji typowego przedstawiciela polskiej klasy wyższej. Okazuje się, że stanowi on wypadkową „nastawienia na utylitarność oraz prestiż”, przy czym proporcje, w jakich znajdują one odzwierciedlenie w posiadanych dobrach i w usługach „zależą przede wszystkim od sfery konsumpcji, którą rozpatrujemy" [s. 258]. Wyniki swoich jakościowych badań Goryszewski odnosi do kilku koncepcji ekonomicznych (m.in. Keynesa, Duesenbery’ego, Engla czy Veblena), starając się wyjaśnić ewentualne rozbieżności między nimi a ogólnymi prawidłowościami społeczno-ekonomicznymi. Styl konsumpcji polskiej klasy wyższej okazuje się być hybrydowy, co potwierdza hipotezę Autora, zgodnie z którą styl ten w dużej mierze wynika z zachowania nawyków i stylów konsumpcji z okresu przed osiągnięciem przez respondentów obecnej pozycji społeczno-ekonomicznej (znacznym awansem na drabinie stratyfikacyjnej w ciągu życia).

Problematyka podjęta $\mathrm{w}$ recenzowanym studium jest aktualna $\mathrm{i}$ istotna. Co prawda dotyczy stylów życia stosunkowo niewielkiej grupy społecznej, ale jest to klasa dominująca, a więc, w świetle koncepcji socjologicznych, kreująca style życia pozostałych członków społeczeństwa. Reprezentanci tej grupy w sposób istotny oddziałują na życie „przeciętnych obywateli”, choć stosunkowo rzadko stykają się z nimi w przestrzeni społecznej. Podjęty przez Autora 
obszar badawczy, uzyskane rezultaty i ich interpretacje zachęcają do podjęcia dyskusji, ale też mogą stanowić inspirację do dalszej eksploracji badawczej.

\section{BIBLIOGRAFIA}

Zmiany w życiu Polaków w gospodarce rynkowej, L. Beskid (red.), IFiS PAN, Warszawa 1999. Bylok F., Konsumpcja w Polsce i jej przemiany wokresie transformacji, Seria: Monografie, nr 108, Wydawnictwo Politechniki Częstochowskiej, Częstochowa 2005.

Domański H., Polska klasa średnia, Wydawnictwo Uniwersytetu Wrocławskiego, Wrocław 2002.

Domański H., Społeczeństwa europejskie. Stratyfikacja i systemy wartości, Wydawnictwo Naukowe Scholar, Warszawa 2009.

Dyskursy ubóstwa i wykluczenia społecznego, E. Tarkowska (red.), IFiS PAN, Warszawa 2013. Goryszewski Ł., Style konsumpcji polskiej klasy wyższej, NOMOS, Kraków 2014.

Polacy równi i równiejsi, M. Jarosz (red.), Instytut Studiów Politycznych PAN, Warszawa 2010.

Kozyr-Kowalski S., Mikroklasy i makroklasy społeczeństwa, [w:] Między przeszłością a przyszłościa. Szkice o socjologii i społeczeństwie polskim $w$ dobie przemian ustrojowych, J. Włodarek (red.), Wydawnictwo Naukowe Uniwersytetu im. Adama Mickiewicza, Poznań 1998.

Landes D. S., Bogactwo i nędza narodów: dlaczego jedni są tak bogaci, a inni tak ubodzy, MUZA Warszawa 2010.

Nowak L., Uwarunkowania zachowań konsumenckich młodzieży akademickiej. Eksploracja struktur ukrytych, Wydawnictwo Uniwersytetu Ekonomicznego w Poznaniu, Poznań 2009.

Sassatelli R., Consumer culture. History, theory and politics, SAGE Publications, Los Angeles, London, New Delhi, Singapore 2007.

Wątroba W., Społeczeństwo konsumpcyjne, Wydawnictwo Uniwersytetu Ekonomicznego, Wrocław 2009.

Zawadzka A. M., Duda J., Zakupy, zadowolenie z życia i aspiracje życiowe, czyli jakie zakupy $i$ komu moga podwyższać zadowolenie z życia?, [w:] W supermarkecie szczęścia. O różnorodności zachowań konsumenckich w kontekście jakości życia, M. Grónik-Durose, A. M. Zawadzka (red.), Difin, Warszawa 2012.

\section{SUMMARY}

\section{A book review:}

\section{Łukasz Goryszewski, Styles of consumption of Polish upper class}

\section{NOMOS Publishing House, Kraków 2014, pp. 293}

The author of the text has discussed the study of Łukasz Goryszewski titled Styles of consumption of Polish upper class (2014). In the case of multiplicity of readings on the phenomenon of consumption available on the market, one should pay attention to this position, because it concerns the issue of consumption of a specific group - Polish upper class. The subject of wealth is widely present in the daily press, but it is relatively rarely examined by scientific research. Empirical studies on wealth are much more neglected in comparison to the studies on poverty. The book by Łukasz Goryszewski provides the reader with the insight into the styles of consumption (of selected goods and services: cars, clothes, housing and ways of spending leisure time) of the representatives of the Polish upper class. The analysis of the image of the Polish elite outlined in the selected series and magazines complements the obtained picture. KEY WORDS: consumer culture, styles of consumption, upper class, wealth. 